\title{
Motif Pembangunan Masjid Cheng Ho Surabaya
}

\author{
Suko Susilo, ${ }^{1}$ Eva Putriya Hasanah, ${ }^{2}$ Nur Syam ${ }^{3}$ \\ ${ }^{1}$ Institut Agama Islam Tribakti Kediri, Indonesia \\ ${ }^{2,3}$ Sunan Ampel State Islamic University Surabaya, Indonesia \\ ${ }^{1}$ suko.susilo@iai-tribakti.ac.id, ${ }^{2}$ evapoutriya@gmail.com, ${ }^{3}$ nursyam@uinsby.ac.id
}

\begin{abstract}
This article aims to understand in depth the motives for the construction of the Cheng Ho Mosque. This article uses qualitative research methods and data collection techniques, documentation, and direct observation by using a cross-disciplinary research model. There are two motives found, namely the motive of reason and motive of purpose. The motive behind the construction of this mosque is the fear and trauma related to sentiment towards the Chinese ethnic caused by the past experiences of the Chinese ethnic. While on the motive of the goal, the researcher found that the meaning of the goal is that PITI wants to get a lot of support to get a sense of security. The existence of the Cheng Ho mosque has become a significant icon that can introduce the presence of Chinese Muslims.
\end{abstract}

Keywords: Cheng Ho Mosque, PITI, Motive

\begin{abstract}
Abstrak
Artikel ini bertujuan untuk memahami secara mendalam bagaimana motif pembangunan Masjid Cheng Ho. Artikel ini menggunakan metode penelitian kualitatif dan teknik pengumpulan data dokumentasi dan pengamatan secara langsung. Dengan menggunakan model penelitian crossdisipliner. Terdapat dua motif yang ditemukan yaitu motif alasan dan motif tujuan. Motif alasan yang menjadi pendorong dibangunnya masjid ini adalah rasa takut dan trauma yang menyangkut sentimen pada etnis Tionghoa yang disebabkan pada pengalaman masa lalu etnis Tionghoa. Sedangkan pada motif tujuan, peneliti menemukan bahwa makna tujuannya adalah PITI ingin mendapat banyak dukungan agar mendapat rasa aman. Keberadaan masjid cheng ho telah menjadi ikon besar yang bisa memperkenalkan keberadaan Muslim Tionghoa.
\end{abstract}

Kata Kunci: Masjid Cheng Ho, PITI, Motif

\section{Pendahuluan}

Spiral of Silence merupakan gabungan dua kata dari bahasa inggris yaitu spiral (spiral) yang dalam Bahasa Indonesia berarti sulur batang dan silence (keheningan) sehingga jika digabungkan menjadi spiral keheningan. Spiral keheningan sebenarnya merupakan sebuah teori komunikasi yang dikembangkan oleh peneliti survei dan komunikasi Jerman Elisabeth Noelle-Neumann pada tahun 1960-an dan 1970an yang bermula dari adanya penelitian pemilu yang dilakukan selama kampanye pemilihan federal Jerman tahun $1965 .{ }^{1}$ Terdapat tiga poin asumsi yang ada dalam teori ini yaitu:

1 Thomas Petersen, "Spiral of Silence," web Britanica (blog), 17 November 2020, https://www.britannica.com/topic/spiral-of-silence.

Tribakti: Jurnal Pemikiran Keislaman

Volume 32, Nomor 2, Juli 2021 
pertama, rasa takut pada isolasi sosial. Noelle-Neumann berasumsusi bahwa seseorang akan kurang menyampaikan opininya apabila merasa pendapatnya merupakan bagian dari minoritas. ${ }^{2}$ Sebab, dia merasa takut adanya isolasi sosial yang bisa saja terjadi pada dirinya. Ancaman isolasi ini bisa berbentuk seperti kritik, berpaling dari seseorang, cemberut, menertawakan seseorang, cemoohan dan sebagainya. ${ }^{3}$

Kedua, Individu mencoba iklim opini. Secara umum, penelitian spiral keheningan mengacu pada bagaimana seorang individu melihat dinamika atau perubahan opini yang berkembang di masyarakat. Tentang apakah sudut pandang mereka konsisten atau dapat berubah dengan pendapat mayoritas publik. ${ }^{4}$ Ketiga, perilaku publik dipengaruhi oleh pendapat mayoritas. Seperti halnya yang sudah penulis paparkan di poin pertama bahwa seorang individu takut adanya isolasi sosial. Akibatnya, seseorang lebih cenderung untuk mencari pendapat orang lain tentang persetujuan atau tidak setuju pada isu-isu tertentu. Untuk menghindari isolasi ini, seseorang akan lebih menahan diri untuk menyampaikan pandangannya secara terbuka agar terhindar dari tanda-tanda ketidak setujuan orang lain. Sebaliknya, orang-orang yang merasa memiliki pendapat yang sama dengan kebanyakan orang akan cenderung dengan berani, tanpa rasa takut, dan lantang menyuarakan pendapatnya.

Di sisi lain, bila melihat fenomena Masjid Cheng Ho yang merupakan bangunan masjid unik karena memiliki arsitektur yang berbeda daripada yang lain, yakni pada arsitekturnya memiliki corak kebudayaan Tiongkok yang menonjol. Maka, teori spiral of silence tersebut menjadi tidak relevan. Sebab, masjid ini digagas oleh Muslim Tionghoa yang tergabung dalam Persatuan Islam Tionghoa Indonesia (PITI) yang mana terdapat beberapa faktor kuat yang bisa membuat Muslim tionghoa baik secara individu maupun organisasi tidak memiliki kepercayaan diri untuk menyampaikan pendapat atau gagasannya terlebih untuk mengekspresikan identitas dan kebudayaannya melalui sebuah bangunan.

${ }^{2}$ Noelle-Neumann E, "Turbulences in the climate of opinion: Methodological applications of the spiral of silence theory," Public Opinion Quarterly 1, no. 1 (1977): 143-58, https://doi.org/158. doi: https://doi.org/10.1086/268371; dalam Carlina DiRusso, "Intentions and Behaviors: Testing Spiral of Silence in a Social Media Context," ETD Archive (blog), 2017, https://engagedscholarship.csuohio.edu/etdarchive/993.

${ }^{3}$ DiRusso, "Intentions and Behaviors: Testing Spiral of Silence in a Social Media Context."

${ }^{4} \mathrm{E}$, "Turbulences in the climate of opinion: Methodological applications of the spiral of silence theory"; Ho, Chen \& Shin 2018 dalam DiRusso, "Intentions and Behaviors: Testing Spiral of Silence in a Social Media Context,". 
Faktor-faktor tersebut antara lain: 1.) Meski PITI merupakan organisasi Islam Indonesia, secara identitas PITI tidak bisa dipisahkan dari suku tionghoa yang merupakan bagian dari minoritas di Indonesia. 2.) Melihat pada sejarah, masyarakat Tionghoa di Indonesia memiliki pengalaman yang sangat buruk. Seperti peristiwa Gerakan 30 Sepuluh Nopember (G30SPKI), peraturan pada masa orde baru yang mengikat dan membatasi ruang lingkup etnis tinghoa, kerusuhan pada saat krisis 1997 yang mana etnis Tionghoa banyak menjadi korban. 3.) Dan masih tingginya sentimen ras pada etnis Tionghoa di Indonesia. Bahkan kebencian kepada masyarakat etnis Tionghoa ini bisa dilacak hingga empat ratus tahun yang lalu. ${ }^{5}$ Sehingga, dengan adanya faktor-faktor tersebut seharusnya terdapat rasa takut bagi mereka untuk mengekspresikan gagasannya.

Meski dikatakan keberadaan Masjid Cheng Ho ini ditujuhkan untuk keperluan syiar Islam namun dalam konteks akademik, penelitian yang membahas soal asjid Cheng Ho telah banyak menunjukkan bahwa masjid ini bukan hanya sekedar sebagai media dakwah semata. Baik penelitian yang mengkaji dari segi nilai-nilai budaya, maupun relevansinya dengan politik hubungan antara Indonesia dan Tiongkok. Sedangkan, penelitian terkait dorongan terbesar pembangunan masjid ini belum pernah ada. Maka hal ini sangat menarik untuk dikaji secara lebih mendalam. Sejalan dengan hal tersebut, dari cara pandang fenomenologi mengatakan, setiap tindakan yang dilakukan oleh manusia mengandung makna atau motif tertentu yang menjadi motivasinya. Oleh karena itu, untuk mengetahui lebih dalam terkait dengan dasar alasan/motif/maknapembangunan masjid chenghoo ini, maka peneliti akan menggunakan pendekatan fenomenologi pada penelitian ini.

Adanya penelitian terdahulu dalam tulisan ini bertujuan untuk menunjukkan orisinalitas topik yang di angkat oleh peneliti. Adapun berdasarkan pencarian peneliti terdapat beragam artikel dengan tema Masjid Cheng Ho berikut ini :

Pertama, artikel terkait Masjid Cheng Ho yang ditulis oleh Muhammad Ali Ridho dan Ahmad Marzuki, dengan judul "Strategi Masjid Cheng Ho Dalam Meningkatkan Pendidikan Keagamaan Muslim Tionghoa Di Surabaya Dan Jember” Journal Multicultural of Islamic Edication Program Magister Pendidikan Agama Islam Multikultural Universitas Yudharta Pasuruan. Volume 3, Nomor 1, Oktober 2019. Penelitian menjelaskan tentang bagaimana Strategi Masjid Cheng Ho dalam

5 Arman Dhani, “'Sejarah Kebencian Terhadap Etnis Tionghoa," diakses 20 Januari 2020, http://tirto.id.

Tribakti: Jurnal Pemikiran Keislaman

Volume 32, Nomor 1, Juli 2021 
Meningkatkan Pendidikan Keagamaan Muslim Tionghoa yang memiliki akses sulit untuk mendapatkan pendidikan agama.

Kedua, artikel dengan judul "Masjid Cheng Hoo Surabaya Seni Bangunan, Ornamen, Dan Kaligrafi" oleh Hermita Titisari dan Salamun yang terbit di Jurnal Pendidikan Seni Rupa,Volume 3 Nomor 3 Tahun 2015, 027-034. Berbicara tentang keunikan dan latar belakang Masjid Cheng Ho dilihat dari sisi seni, ornamen dan kaligrafi.

Ketiga, artikel berjudul Masjid Jami’ Piti Muhammad Cheng Hoo Purbalingga: Refleksi Akulturasi Budaya Pada Masyarakat Purbalingga, yang ditulis Risca Damayanti, Triyanto, dan Muh. Ibnan Syarif pada jurnal Catharsis: Journal of Arts Education UNNES mengangkat gagasan dan ide yang tekandung di dalam Masjid Cheng Ho. Temasuk akuturasi budaya Muslim Jawa dan Tionghoa.

Keempat, artikel tulisan Eko Crys Endrayadi dengan judul "Pendirian Masjid Cheng Ho: Sebuah Simbol Identitas Cina Muslim dan Komoditas Wisata Religius di Surabaya" yang terbit pada jurnal Historia, Vol. 1, No. 2 - Januari 2019. Penelitian ini melihat bagaimana pengaruh Masjid Cheng Hoountuk membangun simbol akn identitas Tioghoa Muslim di Indonesia dan bagaimana masjid tersebut mampu menarik sebagai salah satu tempat pariwisata religi.

Kelima, artikel tulisan J.M. Sri Narhadi, dengan judul "Kajian Bentuk, Fasad, dan Ruang dalam pada masjid Cheng Ho Palembang” Volume 2 - Nomor 3 - Oktober 2019. Penelitian ini menitik beratkan pada bentuk bangunan dan lebih spesifik Masjid Cheng Ho yang dieliti terletak di daerah Palembang.

Keenam, artikel berjudul "Kajian Ikonografi Ornamen pada Interior Masjid Cheng Hoo Surabaya" yang ditulis oleh Tasha Victoria Tanaja dan Lintu Tulistyantoro, pada JURNAL INTRA Vol. 5, No. 2, (2017) 174-181. Penelitian ini melihat ornamen yang ada dalam masjid chengho Surabaya ditinjau teori Ikonografi Panofsky.

Ketujuh, artikel tulisan Bastian Yunariono, dengan judul "Identitas Hibriditas Masjid Tionghoa Muslim di Indonesia” pada jurnal BioKultur, Vol. VIII/No.2/JuliDesember 2019. Jurnal ini memfokuskan untuk melihat Masjid Cheng Ho dari pendekatan Etnografi. Di dalamnya pula menjelaskan sebenarnya masjid dengan menampilkan budaya tionghoa sudah ada sejak dulu namun pudar ketika orde baru dan kembali pasca reformasi.

Kedelapan, artikel berjudul "The Role of Cheng Ho Mosque The New Silk Road, Indonesia-Tiongkok Relations in Islamic Cultural Identity” yang ditulis oleh Choirul 
Mahfud, Journal of Indonesia Islam Volume 08, Number 01, June 2014. Pada artikel ini, peneliti fokus untuk melihat bagaimana Masjid Cheng Ho di Indonesia dapat berkontribusi untuk menjaga dan mempererat hubungan Indonesia dan Tingkok. Penelitian ini banyak memaparkan peran-peran Masjid Cheng Ho dalam beragam aspek.

Kesembilan, skripsi dengan judul "Karakteristik Dan Makna Simbolik Masjid Muhammad Cheng Hoo Makassar" tulisan Nurma Juwita dari Universitas Negeri Makassar 2019. Sama halnya dengan penelitian sebelumnya, penelitian ini mencoba melihat lebih dekat simbol-simbol yang ada dalam bangunan masjid. Namun lebih spesifik masjid yang ditelitih terletak di makasar

Kesepuluh, skripsi berjudul "Bentuk Dan Makna Pada Ragam Hias Masjid Jami' Piti Muhammad Cheng Hoo Purbalingga” yang ditulis Imam Ramadhan Bagus Panuntun dari Universitas Negeri Yogyakarta 2018 menitik beratkan pada ragam arsitektur masjid chenghoo di Purbalingga.

Terdapat banyak penelitian terkait dengan Masjid Cheng Ho baik secara langsung menjadikannya sebagai objek penelitian maupun membahasnya untuk memperkuat asumsi atau pendapat pada penelitian dengan objek lain namun tetap terkait dengan Masjid Cheng Ho. Aspek yang ditelitipun beragam namun secara fokus Masjid Cheng Ho sebagai objek lebih banyak di kaji dari sisi arsitektur dan seni meski ada pula kajian yang memfokuskan pada aspek lain tetapi tidak banyak. Secara garis besar penelitian dengan tema mencari makna dari sudut pandang feminologi belum pernah dilakukan, sehingga bisa dikatakan tema yang di angkat oleh peneliti pada jurnal ini adalah yang pertama.

\section{Metode}

Setiap ilmu pengetahuan memiliki paradigma nya masing-masing. Paradigma memiliki arti sebagai pandangan mendasar terkait dengan sasaran/objek kajian ilmu pengetahuan oleh para ahli.Sehingga ilmu pengetahuan terbagi menjadi beragam kategori. Meskipun dalam pembagian katagori tersebut terdapat perbedaan, namun hakikatnya ilmu pengetahuan di bagi menjadi beragam katagori dan masing-masing ilmu pengetahuan di dalam katagori tersebut memiliki pandangan dasar dari masing-masing ahli. ${ }^{6}$ Seperti paradigma ilmu dakwah akan berbeda dengan paradigma sosiologi,

${ }^{6}$ George Ritzer, Sosiologi Ilmu Pengetahuan Berparadigma Ganda. (Jakarta: Rajawali Press, 1995); dalam Nur Syam, "'Paradigma dan Teori Ilmu Dakwah: Perspektif Sosiologis," Jurnal Ilmiah Syiar 20, no. 1 (2020): 1-18.

Tribakti: Jurnal Pemikiran Keislaman

Volume 32, Nomor 1, Juli 2021 
komunikasi, ekonomi, hukum dan paradigma ilmu lainnya. Namun, untuk mengembangkan sebuah ilmu pengetahuan diperlukan penelitian yang bersifat integratif. Baik yang sifatnya satu rumpun maupun lintas rumpun, dua ilmu pengetahuan maupun lebih. Dalam artikel ini, peneliti menggunakan model crossdisipliner, yakni sebuah model pengembangan ilmu pengetahuan dengan menggunakan dua ilmu atau lebih yang berbeda rumpun, yang mana sebuah ilmu akan menjadi objek penelitian sedangkan ilmu yang lain akan menjadi pendekatan. ${ }^{7}$ Pada tulisan ini fenomena dakwah Masjid Cheng Ho sebagai objek kajian akan dianalisis menggunakan teori sosiologi: fenomenologi.

Artikel ini adalah jenis penelitian kualitatif. Adapun teknik pengumpulan data yang digunakan adalah dokumentasi dan observasi. Teknik dokumentasi adalah cara menghimpun data melalui berbagai informasi yang terdokumentasikan seperti buku, majalah, jurnal, skripsi, tulisan di media dan tulisan di web resmi. ${ }^{8}$ Sedangkan observasi merupakan jenis pengumpulan data dengan cara pengamatan terhadap segala hal terkait dengan sasaran penelitian. ${ }^{9}$ Melalui dua metode ini kemudian informasi-informasi yang peneliti himpun akan diolah menjadi sebuah data dan dianalisa guna menjawab pertanyaan dalam artikel ini.

\section{Pembahasan}

\section{Sejarah Masjid Cheng Ho}

Bangunan yang berumur hampir 18 tahun ini pertama kali berdiri di kota Surabaya. Namun dengan seiring perkembangannya, saat ini Masjid Cheng Hoo telah tersebar di 13 Kota di Indonesia. Masjid tersebut terinspirasi dari adanya masjid di Tiongkok yang berdiri sejak 996 Masehi yakni masjid Niu Jie di Beijing. Masjid Cheng Hoo merupakan sebuah bangunan masjid yang di gagas oleh HMY Bambang Sujanto dan rekan-rekan nya yang tergabung dalam Persatuan Islam Tionghoa Indonesia (PITI) Jawa Timur. ${ }^{10}$ PITI sendiri merupakan sebuah organisasi masyarakat yang menjadi rumah bagi orang-orang tionghoa Muslim di Indonesia.

\footnotetext{
${ }^{7}$ Nur Syam, “Agenda Penelitian Islamic Studies Bidang Sosial, Ekonomi, Pendidikan dan Hukum,” t.t., http://nursyamcentre.com/Artikel.

${ }^{8}$ Nanang Martono, Metode Penelitian Kuantitatif : Analisis Isi dan Analisis Data Sekunder (Jakarta: PT Raja Grafindo, 2016).

${ }^{9}$ Martono.

${ }^{10}$ Majalah Cheng Ho, "Cheng Ho : Walisongo dan Muslim Tionghoa Indonesia Dimasa Lalu, Kini dan Esok," Komunitas : Media Informasi \& Komunikasi Pembina Iman Tauhid Islam d/h Persatuan Islam Tionghoa Indonesia, 2008, edisi khusus No. 40-April edisi. 
Berdasarkan sejarah, PITI sudah ada sejak sebelum kemerdekaan yaitu pada tahu 1931 dengan nama Persatuan Islam Tionghoa (PIT) di Kota Deli Serdang, Sumatera Utara yang dibentuk oleh Tionghoa Muslim bernama Haji Yap Siong. Dia adalah seorang muallaf dari Kota Moyen, Tiongkok. Selanjutnya, dibentuk pula Persatuan Tionghoa Muslim (PTM) pada tahun 1953 sebagai organisasi yang menaungi tionghoa Muslim di Jakarta. Kedua organisasi ini merupakan cikal bakal terbentuknya PITI. Sebab, terbentuknya PIT dan PTM tidak bisa mencakup seluruh tionghoa Muslim karena sifatnya yang lokal maka kedua organisasi ini melebur menjadi satu ke dalam organisasi bernama PITI pada 1954. Namun, seiring dengan perkembangannya terdapat banyak tantangan yang harus dihadapi oleh PITI salah satunya adalah terjadi perbedaan politik di dalam tubuh PITI sehingga menyebabkannya bubar pada $1955^{11}$ dan kembali dibentuk pada 14 April 1961 di Jakarta. ${ }^{12}$ Tantangan juga datang dari luar tubuh PITI yaitu pada masa orde baru terdapat peraturan yang mengatur tentang larangan menggunakan simbol, identitas, bahasa dan budaya asing khususnya Tiongkok pada masa itu. Sehingga PITI pun harus berubah nama menjadi Pembina Iman Tauhid Islam pada 15 Desember $1972^{13}$ dan kembali lagi menjadi Persatuan Islam Tionghoa Indonesia pada tahun 2000.

Kehadiran PITI bertujuan untuk syiar Islam. Hal tersebut tercantum dalam AD/ART PITI bahwa Visi PITI adalah mewujudkan Islam sebagai rahmatan lil alamin (Islam sebagai rahmat bagi sekalian alam). ${ }^{14}$ Menurut PITI, organisasi ini selain menjadi tempat bagi Tionghoa Muslim juga akan berdakwah di kalangan masyarakat Tionghoa, baik pada orang-orang yang sudah menjadi Muslim maupun yang belum menjadi Muslim. ${ }^{15}$ Sedangkan pada misi nya, PITI akan menjadi jembatan dari berbagai kalangan yaitu Muslim Tionghoa dengan Muslim Indonesia, Muslim Tionghoa dengan etnis Tionghoa non Muslim dan etnis Tionghoa dengan umat Islam. ${ }^{16}$ Hal ini juga dipahami

${ }^{11}$ Khozyn Arief, "Sejarah dan Perkembangan PITI Kiprah PITI di Gelanggang Nasional” (Seminar dan Musyawarah Wilayah PITI DIY, Yogyakarta, 1994); dalam Eva Putriya Hasanah, "Peran Persatuan Islam Tionghoa (PITI) Jawa Timur dalam Membantu Pemerintah Tiongkok untuk Mempererat Hubungannya dengan Pemerintah Indonesia" (skripsi, Surabaya, Universitas Islam Negeri Sunan Ampel, 2019).

12 Junus Jahja, Sang Pemula Karim Oei Nasionalis Indonesia, Muslim Taat dan Pengusaha Sukses (Jakarta: Yayasan Haji Karim Oei, 2005), 3; dalam Hasanah, "Peran Persatuan Islam Tionghoa (PITI) Jawa Timur dalam Membantu Pemerintah Tiongkok untuk Mempererat Hubungannya dengan Pemerintah Indonesia."

13 Arief, "Sejarah dan Perkembangan PITI Kiprah PITI di Gelanggang Nasional."

14 AD/ART/PITI, 2012.

15 AD/ART/PITI, 7.

${ }^{16} A D / A R T / P I T I, 5$.

Tribakti: Jurnal Pemikiran Keislaman

Volume 32, Nomor 1, Juli 2021 
oleh Anne Dickson sebagaimana dikutip oleh Choirul Mahfud bahwa PITI menjadi media yang merangkul semua pihak tanpa perbedaan suku, etnis maupun agama. ${ }^{17}$

PITI sebagai pendiri Masjid Cheng Ho, dengan berkaca pada visi-misi nya bisa dikatakan bahwa pembangunan masjid ini selaras dengan AD-ART tersebut yaitu sebagai dakwah Islam. Melalui Yayasan Haji Muhammad Cheng Hoo yang dibentuk untuk mengelola fasilitas yang disediakan di masjid tersebut, terdapat beragam program sebagai langkah dakwah Islam. Program-program tersebut seperti pembinaan muallaf, ${ }^{18}$ perayaan Hari Besar Islam seperti Idul Adhah, khitanan masal serta sholat jum'at berjama'ah, lomba MTQ Nasional yang di ikuti oleh masjid Cheng Hoo seluruh Indonesia, buka puasa bersama anak yatim, pengajian mingguan dan bulanan yang mana pengajian ini tidak hanya diikuti oleh tionghoa Muslim tetapi juga non-tionghoa Muslim. ${ }^{19}$ Terdapat juga pertukaran ulama seperti dari Muhammadiyah, Nahdlatul Ulama dan Majelis Ulama Indonesia (MUI) ke Tiongkok dan sebaliknya dari Tiongkok ke Indonesia. Hal unik lain yang terjadi pada pola dakwah melalui Masjid Cheng Hoo ini adalah perayaan Imlek yang di kemas dengan cara yang lebih Islami, seperti santunan anak yatim dan lainnya. ${ }^{20}$

Mengutip dari majalah Haji Muhammad Cheng Hoo, masjid ini memang dibangun guna menjadi simbol atau prasasti yang menunjukkan bahwa terdapat pula orang-orang Tionghoa yang menjadi Muslim serta sebagai simbol kebebasan beragama di Indonesia. ${ }^{21}$ Oleh karena itu, masjid tersebut sangat kental dengan ciri khas budaya Tionghoa dan dipaduhkan dengan budaya-budaya Islam. Nama Cheng Hoo sendiri diambil untuk mengenang Laksamana Cheng Hoo atau Zheng. Ditinjau dari model masjid chenghoo, setiap bangunan yang ada melambangkan sebuah arti. Misalnya, dominasi warna kuning, hijau, dan merah serta gaya arsitektur Masjid Cheng Hoo dengan model klenteng sebagai simbol untuk menunjukkan identitas nenek moyang orang-orang Tionghoa yang banyak beragama Budha. Pada bagian atas bangunan utama yang memiliki bentuk 8 (Pat Kwa) yang memiliki arti jaya dan keburuntungan dalam bahasa

\footnotetext{
${ }^{17}$ Anne Dickson, “A Chinese Indonesian Mosque's Outreach In The Reformasi Era” (paper for the 17 Biennial Conference of the Asian Studies Association of Australia, Melbourne, 2018); dalam Choirul Mahfud, "The Role of Cheng Ho Mosque The New Silk Road, Indonesia-Tiongkok Relations in Islamic Cultural Identity," Journal of Indonesia Islam 08, no. 01 (Juni 2014).

18 Burnadi Hasan, "Indahnya Perbedaan : Sejarah Berdirinya Masjid Haji Muhammad Cheng Hoo," masjid cheng hoo, t.t., 91 edisi, 91.

19 Hariyono Ong, Ketua Ta'mir Masjid Cheng Hoo, Agustus 2019; Hasanah, "Peran Persatuan Islam Tionghoa (PITI) Jawa Timur dalam Membantu Pemerintah Tiongkok untuk Mempererat Hubungannya dengan Pemerintah Indonesia," dalam sebuah wawancara dengan penulis, 03 Agustus 2019.

${ }^{20}$ Ong, Ketua Ta'mir Masjid Cheng Hoo. dan Esok."

${ }^{21}$ Majalah Cheng Ho, "Cheng Ho : Walisongo dan Muslim Tionghoa Indonesia Dimasa Lalu, Kini
} 
Tionghoa. Dari sisi Islam, bangunan utama masjid ini berukuran 11x9 meter. Angka 11 meter melambangkan ukuran ka'bah yang pertama kali di bangun oleh Nabi Ibrahim AS dan sedangkan ukuran 9 meter sebagai simbol dari keberadaan Wali Songo yang telah berdakwah menyebarakan agama Islam di Jawa. Disamping itu terdapat pula relief pada sisi kanan masjid yang menggambarkan Muhammad Cheng Hoo bersama armada dalam samudera Hindia. ${ }^{22}$ Pada beberapa sumber mengatakan bahwa Cheng Hoo merupakan seorang Muslim yang pernah melakukan syiar Islam di Indonesia. Konsep keterbukaan juga di bangun oleh masjid ini dengan keberadaan konsep masjid tanpa memiliki pintu. ${ }^{23}$

Tidak hanya sebagai tempat beribadah, yayasan Cheng Hoo tersebut telah menyediakan beragam fasilitas dan melakukan banyak kegiatan. Hal tersebut sejalan dengan yang disampaikan oleh Haryono Ong sebagaimana yang dikutip oleh Eva, bahwa Masjid Cheng Ho digunakan untuk berbagai kegiatan seperti budaya, agama, dan berbagai kegiatan sosial seperti amal, pelayanan sosial dan donor darah. ${ }^{24}$ Pertama, dari aspek pendidikan Masjid Cheng Hoo menyediakan fasilitas TK (Taman Kanakkanank). ${ }^{25}$ Selain itu, disediakan buku praktis belajar bahasa Mandarin. Kedua, dalam aspek kesehatan. Masjid ini menyediakan klinik akupuntur, yang merupakan salah satu metode pengobatan asal Tiongkok kuno. ${ }^{26}$ Ketiga, fasilitas seni dan olaraga seperti paduan suara dan tersedianya lapangan olaraga di depan masjid. ${ }^{27}$ Keempat, ketersediaan media pendukung seperti majalah Cheng Hoo, situs web dan buku. Di dalamnya banyak menjelaska tentang berbagai identitas maupun budaya Tionghoa baik secara langsung maupun hanya tersirat. Misal pada majalah edisi khusus dengan judul "Cheng Ho Walisongo dan Muslim Tionghoa Indonesia di Masa Lalu, Kini dan Esok”. Di dalamnya tidak hanya memuat pembahasan tentang sejarah pembangunan Masjid Cheng Ho tetapi beberapa bagian telah banyak memperlihatkan kebudayaan Tionghoa dan penjelasan tentang kisah syiar Islam laksamana Cheng Ho di Indonesia. ${ }^{28}$ Dengan berbagai fasilitas dan program yang tersediah masjid cheng ho tidak hanya menjadi sebuah bangunan biasa

${ }^{22}$ Majalah Cheng Ho.

${ }^{23}$ HMY. Bambang Sujanto, (Penasihat PITI Jatim) dalam sebuah wawanca, 12 September 2013 dalam Mahfud, "The Role of Cheng Ho Mosque The New Silk Road, Indonesia-Tiongkok Relations in Islamic Cultural Identity."

${ }^{24}$ Hasanah, "Peran Persatuan Islam Tionghoa (PITI) Jawa Timur dalam Membantu Pemerintah Tiongkok untuk Mempererat Hubungannya dengan Pemerintah Indonesia,” Hariyono Ong.

${ }^{25}$ Hasan, "Indahnya Perbedaan : Sejarah Berdirinya Masjid Haji Muhammad Cheng Hoo," 93.

${ }^{26}$ Hasan, 90.

${ }^{27}$ Hariyono Ong Hasanah, "Peran Persatuan Islam Tionghoa (PITI) Jawa Timur dalam Membantu Pemerintah Tiongkok untuk Mempererat Hubungannya dengan Pemerintah Indonesia."

${ }^{28}$ Hasan, "Indahnya Perbedaan : Sejarah Berdirinya Masjid Haji Muhammad Cheng Hoo."

Tribakti: Jurnal Pemikiran Keislaman

Volume 32, Nomor 1, Juli 2021 
yang memberikan tempat ibadah bagi agama Islam atau bagi kepentingan syiar Islam saja melainkan sebagai media pengenalan nilai-nilai budaya etnis tionghoa. Keberadaan masjid Cheng Ho ini juga mampu menjadi daya tarik bagi banyak orang, baik masyarakat domestik maupun mancanegara bahkan menjadi ikon Kota Surabaya.

\section{Masjid Cheng Hoo dalam Paradigma Ilmu Dakwah}

Paradigma merupakan pandangan mendasar dari para ahli tentang apa yang menjadi subjek kajian ilmu. Setiap ilmu pengetahun memiliki paradigma nya masingmasing. ${ }^{29}$ Sehingga dalam konteks dakwah, paradigma dapat diartikan menjadi bagaimana pandangan ahli ilmu dakwah terhadap subject of metter (sasaran kajian sebuah ilmu). Terdapat lima paradigma ilmu dakwah menurut ahli yakni:

Pertama, developmentalism merupakan sebuah penciptaan model atau produk, baik yang sudah ada maupun belum ada agar dapat bermanfaat bagi masyarakat. Kedua, partisipatori, sama halnya dengan developmentalism, paradigma ini juga merupakan sebuah penciptaan model maupun produk yang bermanfaat bagi masyarakat. Namun, perbedaannya adalah dalam pengembangan ini masyarakat dilibatkan secara aktif. Ketiga, faktor yakni hubungan antar faktor dakwah seperti da'i, pesan dakwah, media, metode dengan efek perubahan sikap pelaku. Keempat, interpretatif yakni menurut para ahli bahwa yang menjadi sasaran kajian adalah sebuah realitas yang mengandung makna. Realitas tersebut berupa tindakan individu yang berkaitan dengan dakwah. Tindakan tersebut bisa berupa ide, gagasan dan tindakan individu. Kelima, sistem adalah keterkaitan dan tidak dipisahkan antara sub sistem dakwah yang bersifat problem solving. ${ }^{30}$

Artikel ini menggunakan paradigma interpretatif, yang mana peneliti mengangkat Masjid Cheng Ho sebagai sasaran kajian penelitian. Peneliti menganggap bahwa Masjid Cheng Ho merupakan sebuah bentuk/ide/gagasan dakwah yang unik atau berbeda dari yang lain. Baik dari segi arsitektur masjid maupun dari penggagas dan yang berpartisipasi dalam pembangunan masjid ini yaitu tidak hanya dari kalangan Muslim Tionghoa namun juga Tionghoa non-Muslim yang berpatisipasi dalam hal finansial. Sehingga sangat menarik untuk di kaji lebih dalam sebagai sasaran atau objek kajian terkait dengan motif pendorong yang menyebabkan dibangunnya masjid ini. Dengan menggunakan teori

${ }^{29}$ Ritzer, Sosiologi Ilmu Pengetahuan Berparadigma Ganda.; dalam Syam, “"Paradigma dan Teori Ilmu Dakwah: Perspektif Sosiologis."

${ }^{30}$ Syam, "Paradigma dan Teori Ilmu Dakwah: Perspektif Sosiologis."” 
fenomenologi, penelitian ini akan mengkaji secara mendalam untuk menemukan makna dibalik tindakan pembangunan masjid ini.

\section{Analisis Makna di Balik Pembangunan Masjid Cheng Ho}

Sebagai model dakwah yang unik, Masjid Cheng Ho memiliki daya Tarik tersendiri untuk dipahami lebih dalam terkait motif atau makna nya. Seperti halnya yang telah peneliti jelaskan pada sub-bab sebelumnya bahwa peneliti akan mencoba untuk menemukan makna baik dari pandangan Max Webber yakni in order to motive atau terkait dengan motif tujuan dan Alfred Schultz yakni because motive yang lebih mengacu pada alasan dilakukannya sebuah tindakan.

Masjid Cheng Ho di gagas oleh MHY Bambang Sujanto, merupakan seorang etnis Tionghoa Muslim yang berkewarganegaraan Indonesia. Sujanto ini merupakan bagian dari PITI Jawa Timur. Sehingga apabila melihat pada sumber publikasi Masjid Cheng Ho menuliskan bahwa bangunan Masjid Cheng Ho diinisiasi Sujanto bersama dengan temantemannya di PITI Jawa Timur.

Peneliti menemukan bahwa motif dasar yang menjadi alasan atau pendorong dibentuknya Masjid Cheng Ho (because motive) adalah ketakutan atau rasa trauma masa lalu yang menyangkut sentimen pada etnis Tionghoa sehingga dibangunnya Masjid Cheng Ho untuk mencari rasa aman. Terdapat beberapa faktor yang menjadikan alasan ini begitu kuat yakni: pertama, tidak bisa dipungkiri bahwa keberadaan etnis Tionghoa merupakan salah satu penduduk minoritas di masyakat Indonesia. Meski terdapat beragam etnis di Indonesia, namun etnis ini cukup mendapat banyak sorotan akibat faktor sejarah atau kejadian di masa lalu. Sama hal nya dengan Tionghoa Muslim, bisa dikatakan bahwa mereka adalah sebuah minoritas di dalam minoritas itu sendiri.

Kedua, pengalaman di masa lalu. Banyak catatan sejarah menyebutkan bahwa seringkali terjadi konflik antara etnis Tionghoa dengan etnis lain di Indonesia baik pada masa pra kemerdekaan maupun sesudah kemerdekaan serta seringkali berujung pada kekerasan, kerusuhan, pembunuhan yang berdampak pada masyarakat Tionghoa. Salah satu peristiwa di masa lalu yang menyebabkan sentimen pada etnis ini muncul adalah peristiwa G 30 S/PKI. Peristiwa tersebut merupakan sebuah pemberontokan yang terjadi di Indonesia pada 30 September 1965 yang dipercayai oleh banyak orang bahwa pelaku di balik kejadian tersebut adalah Partai Komunis Indonesia (PKI) dan melibatkan 
masyarakat etnis Tionghoa. Akibat kejadian tersebut, sentimen-sentimen pada etnis ini selalu muncul karena selalu diidentikan dengan gerakan komunis. ${ }^{31}$

Ketiga, mayoritas penduduk Indonesia adalah penduduk Muslim sehingga keberadaan PITI seharusnya bisa menjadi payung yang bisa melindungi masyarakat Tionghoa setidaknya bagi mereka yang beragama Islam. Berdasarkan sejarah, cikal bakal PITI sudah ada sejak sebelum kemerdekaan dan secara resmi menjadi PITI pada 1954. Ini artinya eksistensi etnis Tionghoa sebagai Muslim sudah ada sejak lama tapi nyatanya tidak cukup kuat membuat etnis Tionghoa terhindar dari sentimen komunis pada masa itu. Bahkan akibat terjadinya peristiwa G 30 S/PKI, PITI turut menerima dampaknya. Peraturan yang dikeluarkan oleh presiden pada masa itu menyebabkan PITI harus berganti nama menjadi Pembina Iman Tauhid Islam. Hal tersebut menunjukkan, keberadaan PITI meski sebagai organisasi masyarakat Islam tidak cukup kuat untuk melindungi diri bahkan bagi Tionghoa Muslim sekalipun.

Sehingga berdasarkan pada asumsi peneliti, masyarakat Muslim Tionghoa membutuhkan sebuah hal yang baru agar bisa melindungi dirinya. Salah satu cara yang bisa melindungi dirinya adalah dengan mendapatkan dukungan dari banyak pihak. Maka keberadaanya sebagai minoritas menjadi aman. Menurut peneliti, hal ini berkaitan dengan motif tujuan (in order to motive) oleh Weber.

Masjid Cheng Ho menjadi bangunan representatif bagi PITI yang memperkenalkan kepada masyarakat bahwa etnis Tionghoa juga ada yang menjadi seorang Muslim. Bangunan masjid ini mampu menarik perhatian banyak orang. Hal tersebut ditunjukkan dengan banyaknya pengunjung yang datang ke masjid tersebut, baik Tionghoa Muslim maupun non-Muslim, masyarakat pada umumnya, dari dalam negeri maupun manca negara seperti Malaysia, Inggris, Tiongkok, Belanda, Singapura, Thailand, Amerika, Hongkong, Taiwan, Arab dan India. Terdapat pula kunjungan dari universitas dan Non-Governmental Organization (NGO), seperti dari Universitas Darussalam Gontor Ponorogo, ${ }^{32}$ sedangkan dari NGO adalah Global Peace Foundation Indonesia. Di awal dibentuknya saja, di masjid Cheng ho terdapat kurang lebih 600 orang yang melakukan sholat jum'at di masjid ini, bahkan rata-rata tiap bulan terdapat 4 sampai 5 orang berbagai suku yang masuk Islam. Sehingga membuat masjid ini masuk dalam

${ }^{31}$ Hasanah, "Peran Persatuan Islam Tionghoa (PITI) Jawa Timur dalam Membantu Pemerintah Tiongkok untuk Mempererat Hubungannya dengan Pemerintah Indonesia."

${ }^{32}$ Hasan, "Indahnya Perbedaan : Sejarah Berdirinya Masjid Haji Muhammad Cheng Hoo." 
MURI. ${ }^{33}$ Sehingga situasi ini ikut serta mendukung dalam memperkenalkan budaya Tionghoa khususnya keberadaan Muslim Tionghoa pada khalayak. Tujuannya adalah agar mereka semakin dikenal banyak orang dan mendapat dukungan.

Di samping itu, dengan segala fasilitas yang diberikan oleh masjid ini dan beragam program yang dimiliki nya seperti santunan anak yatim, perayaan Hari Besar Negara dan Hari Besar Islam, akan ikut serta membentuk persepsi atau pandangan masyarakat. Tidak hanya melihat Tionghoa juga sebagai seorang Muslim melainkan juga melihat masyarakat Tionghoa dari sisi yang lebih positif. Hal demikian juga di perkuat dengan pernyataan penggagas Masjid Cheng Ho, Bambang Sujanto, bahwa sebelum membangun Masjid Cheng Ho ini banyak orang yang mengetahui dan memahami keberadaan orang-orang Tionghoa di Indonesia khususnya Tionghoa yang menjadi Muslim. Namun sejak berdirinya bangunan tersebut membuat banyak orang mengenal dan mulai menghargai masyarakat Tionghoa baik dari sisi identitas, agama maupun budaya. $^{34}$

Langkah lain yang dilakukan oleh PITI untuk mendapat banyak dukungan adalah dengan melibatkan semua pihak. Indikasinya adalah dalam pembangunan masjid Cheng ho, PITI tidak hanya melibatkan Tionghoa Muslim tapi juga Tionghoa non-Muslim juga berpartisipasi dalam memberikan dukungan dari segi finansial. Dalam acara peresmian pun, dihadiri dari berbagai elemen seperti dari pihak pemerintah seperti Gubernur dan Menteri Agama Indonesia pada saat itu, ketua Nahdlatul Ulama', ketua Muhammadiyah, Kedutaan Besar Tiongkok, Kedutaan Besar Amerika Serikat dan tokoh-tokoh yang lain.

Selanjutnya makna motif tujuan ini juga bisa dilihat melalui pemaparan Sujanto, bahwa bangunan ini menjadi bagian dari misi Muslim Tionghoa di Indonesia untuk dapat berperan aktif dalam berkontribusi, bernegosiasi dan memperkuat identitas sebagai ormas Islam pada umumnya. Menurutnya, misi ini cukup berhasil karena mendapatkan dukungan dari banyak pihak. ${ }^{35}$ Eksistensi PITI di masyarakat Indonesia semakin terlihat. PITI dianggap mampu menjadi mediator yang bisa menghubungkan beragam pihak. Misalnya pada kasus Muslim Uighur di Tiongkok yang menyebabkan banyak dan Esok."

${ }^{33}$ Majalah Cheng Ho, "Cheng Ho : Walisongo dan Muslim Tionghoa Indonesia Dimasa Lalu, Kini

${ }^{34}$ HMY. Bambang Sujanto, (Penasihat PITI Jatim) dalam sebuah wawanca, 12 September 2013 dalam Hasanah, "Peran Persatuan Islam Tionghoa (PITI) Jawa Timur dalam Membantu Pemerintah Tiongkok untuk Mempererat Hubungannya dengan Pemerintah Indonesia.”

${ }^{35}$ HMY. Bambang Sujanto, (Penasihat PITI Jatim) dalam sebuah wawanca, 12 September 2013 dalam Mahfud, "The Role of Cheng Ho Mosque The New Silk Road, Indonesia-Tiongkok Relations in Islamic Cultural Identity."

Tribakti: Jurnal Pemikiran Keislaman

Volume 32, Nomor 1, Juli 2021 
demonstrasi terjadi dan menyudutkan pihak pemerintah Tiongkok di Indonesia. PITI menjadi mediator saat pertemuan antara PWNU Jawa Timur dan pihak konsulat Jenderal (konjen) Tiongkok di Surabaya. ${ }^{36}$ Pada contoh yang lain PITI juga menjadi mediator saat pembentukan Pusat Kajian Indonesia-Tiongkok, antara pihak Konjen dan Universitas Islam Negeri Sunan Ampel Surabaya. ${ }^{37}$ Melihat hal tersebut, posisi PITI menjadi sangat penting. Sehingga berdasarkan pemaparan diatas, motif tujuan dibentuknya masjid cheng ho adalah agar mendapat banyak dukungan dari berbagai pihak di Indonesia untuk menciptakan rasa aman.

\section{Kesimpulan}

Masjid Cheng Ho adalah sebuah bangunan beribadah bagi umat Islam yang di gagas dan didirikan oleh MHY Bambang Sujanto bersama dengan teman-temannya yang ada dalam organisasi PITI. Terdapat keunikan pada masjid ini yakni bentuk bangunannya yang menyerupai klenteng, lengkap dengan arsitektur yang khas dengan kebudayaan Tiongkok dan dipaduhkan dengan nilai-nilai keIslaman. Tujuan masjid ini adalah untuk keperluan syiar Islam dan menunjukkan bahwa di Indonesia terdapat pula masyarakat Tionghoa yang menjadi Muslim.

Di samping itu, dengan menggunakan pendekatan fenomenologi peneliti menemukan terdapat dua motif atau makna lain yang lebih dalam dan ada di balik pembangunan masjid tersebut. Motif tersebut terbagi menjadi dua yakni motif alasan dan motif tujuan. Motif alasannya adalah ketakutan atau rasa trauma masa lalu yang menyangkut sentimen pada etnis Tionghoa yang disebabkan pada pengalaman masa lalu etnis Tionghoa. Sedangkan dari sisi motif tujuan adalah agar PITI atau orang-orang Muslim Tionghoa mendapat banyak dukungan dari beragam pihak agar mendapat rasa aman dan perlindungan. Dengan adanya rasa takut dan trauma akibat sentimen, maka etnis Tionghoa sebagai entitas minoritas memerlukan banyak dukungan agar bisa melindungi kelompoknya. Kedua motif ini saling berhubungan sebagai dasar makna dari pembentukan Masjid Cheng Ho.

\footnotetext{
36 "Bahas Isu Muslim Uighur, YMHCI-PITI Mediasi PWNU Jatim dengan Konjen RRT," diakses 14 Maret 2019, http://chenghoo.co/2018/12/13/yhmchi-piti-inventarisir-kebakaran-kapasan/.

${ }^{37}$ Hasanah, "Peran Persatuan Islam Tionghoa (PITI) Jawa Timur dalam Membantu Pemerintah Tiongkok untuk Mempererat Hubungannya dengan Pemerintah Indonesia."
} 


\section{Daftar Pustaka}

Arief, Khozyn. "Sejarah dan Perkembangan PITI Kiprah PITI di Gelanggang Nasional." Yogyakarta, 1994.

"Bahas Isu Muslim Uighur, YMHCI-PITI Mediasi PWNU Jatim dengan Konjen RRT." Diakses 14 Maret 2019. http://chenghoo.co/2018/12/13/yhmchi-piti-inventarisirkebakaran-kapasan/.

Dhani, Arman. "'Sejarah Kebencian Terhadap Etnis Tionghoa."” Diakses 20 Januari 2020. http://tirto.id.

Dickson, Anne. "A Chinese Indonesian Mosque's Outreach In The Reformasi Era." Melbourne, 2018.

DiRusso, Carlina. "Intentions and Behaviors: Testing Spiral of Silence in a Social Media Context." ETD Archive (blog), 2017. https://engagedscholarship.csuohio.edu/etdarchive/993.

E, Noelle-Neumann. "Turbulences in the climate of opinion: Methodological applications of the spiral of silence theory." Public Opinion Quarterly 1, no. 1 (1977). https://doi.org/158. doi: https://doi.org/10.1086/268371.

Hasan, Burnadi. "Indahnya Perbedaan: Sejarah Berdirinya Masjid Haji Muhammad Cheng Hoo." masjid cheng hoo, t.t., 91 edisi.

Hasanah, Eva Putriya. "Peran Persatuan Islam Tionghoa (PITI) Jawa Timur dalam Membantu Pemerintah Tiongkok untuk Mempererat Hubungannya dengan Pemerintah Indonesia.” Skripsi, Universitas Islam Negeri Sunan Ampel, 2019.

Jahja, Junus. Sang Pemula Karim Oei Nasionalis Indonesia, Muslim Taat dan Pengusaha Sukses. Jakarta: Yayasan Haji Karim Oei, 2005.

Mahfud, Choirul. "The Role of Cheng Ho Mosque The New Silk Road, IndonesiaTiongkok Relations in Islamic Cultural Identity." Journal of Indonesia Islam 08, no. 01 (Juni 2014).

Majalah Cheng Ho. "Cheng Ho: Walisongo dan Muslim Tionghoa Indonesia Dimasa Lalu, Kini dan Esok.” Komunitas : Media Informasi \& Komunikasi Pembina Iman Tauhid Islam d/h Persatuan Islam Tionghoa Indonesia, 2008, edisi khusus No. 40April edisi.

Martono, Nanang. Metode Penelitian Kuantitatif: Analisis Isi dan Analisis Data Sekunder. Jakarta: PT Raja Grafindo, 2016.

Petersen, Thomas. "Spiral of Silence." web Britanica (blog), 17 November 2020. https://www.britannica.com/topic/spiral-of-silence.

Ritzer, George. Sosiologi Ilmu Pengetahuan Berparadigma Ganda. Jakarta: Rajawali Press, 1995.

Syam, Nur. "Agenda Penelitian Islamic Studies Bidang Sosial, Ekonomi, Pendidikan dan Hukum," t.t. http://nursyamcentre.com/Artikel.

Tribakti: Jurnal Pemikiran Keislaman

Volume 32, Nomor 1, Juli 2021 
. "Paradigma dan Teori Ilmu Dakwah: Perspektif Sosiologis." Jurnal Ilmiah Syiar 20, no. 1 (2020). 